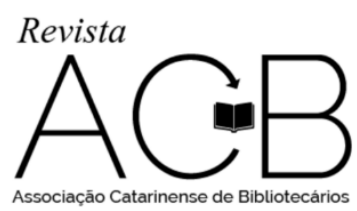

Revista ACB: Biblioteconomia em Santa Catarina, Florianópolis, v. 22, n. 3, p. 450-466, ago./nov., 2017.

\title{
A REFORMA DE 1935: SINALIZANDO A CONSTITUIÇÂO DE BIBLIOTECAS ESCOLARES NO SISTEMA ESTADUAL DE ENSINO DE SANTA CATARINA
}

\begin{abstract}
Alzemi Machado ${ }^{1}$
Resumo: O presente artigo objetiva investigar a reforma do ensino em Santa Catarina ocorrida em 1935, a partir do Decreto n. 713, de 05 de janeiro desse mesmo ano, fortalecida pelas Instruções da Portaria $n^{\circ} 04$ de 13 de janeiro de 1937, documento regulamentador contendo as recomendações para a organização das Bibliotecas Escolares na Rede Pública do Estado de Santa Catarina. Para a consecução da investigação, foram definidas questões norteadoras, objetivando verificar e analisar as estratégias utilizadas pelos dirigentes do Departamento de Educação, bem como as representações que livros e a leitura passam a ter no âmbito da reforma, a partir das prescrições estabelecidas na documentação oficial.
\end{abstract}

Palavras-chave: Reforma Educacional. Legislação do Ensino. Biblioteca Escolar.

\section{INTRODUÇÃO}

A partir da década de 1920, educadores ligados ao movimento de renovação educacional denominado Escola Nova, já enfatizavam a importância do espaço biblioteca na cultura pedagógica escolar. Segundo Lourenço Filho, “[...] ensino e biblioteca são instrumentos complementares. [...] Uma escola sem biblioteca é um instrumento imperfeito. A biblioteca sem ensino, ou seja, sem a tentativa de estimular, coordenar e organizar a leitura, será, por seu lado, instrumento vago e incerto [...]" (LOURENÇO FILHO,1944, p. 3-4).

Este movimento denominado "Escola Nova" teve forte repercussão em alguns estados brasileiros, entre os quais São Paulo, Ceará, Bahia, Minas Gerais, Pernambuco e Distrito Federal, tendo à frente educadores de porte intelectual tais como Anísio Teixeira, Fernando de Azevedo, Lourenço Filho, Pascoal Leme, que articularam sensíveis reformas no cotidiano escolar, repercutindo não somente no aspecto da ampliação da rede escolar, mas também na substituição de todo um ideário educacional vigente, regidos pelos princípios de uma nova teoria educacional representada pelo escola novismo.

Entretanto, a concretização destes novos métodos passava também por modificações no espaço físico escolar, ou seja, a escola deveria dispor de uma infraestrutura que abrigasse museus, laboratórios, gabinetes, bibliotecas, salas de aulas e mobiliários adequados, além de materiais didáticos que proporcionassem um ambiente estimulante e motivador. Livros e bibliotecas entendidos como objetos da cultura material escolar passam assim, a ter novos significados no universo escolar, servindo como instrumentos auxiliares que suscitassem a pesquisa, a reflexão e a adoção de novas práticas de leitura.

\footnotetext{
${ }^{1}$ Mestre em Educação e Cultura pela Universidade do Estado de Santa Catarina (UDESC).
} 


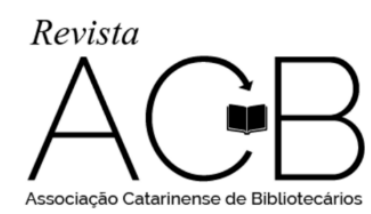

Revista ACB: Biblioteconomia em Santa Catarina, Florianópolis, v. 22, n. 3, p. 450-466, ago./nov., 2017.

O Estado de Santa Catarina realizou diversas reformas no campo da educação elementar ao longo do Século XX. Merece destaque a Reforma Orestes Guimarães efetuada no início da segunda década, e que introduziu inovações na parte didática-pedagógica e na estrutura física das unidades escolares. Entretanto, estas inovações não sinalizavam a criação e a utilização de espaços reservados às bibliotecas escolares, descartando-as das práticas de ensino.

Contudo, a partir da Reforma Trindade instituída pelo Decreto $\mathrm{n}^{\circ} 713$ de 05 de janeiro de 1935, ocasionou um maior desenvolvimento da educação publica, marcada pela expansão do número de escolas e na elevação expressiva nos níveis de matrículas, interferindo no crescimento dos índices de alfabetização das camadas populares. Não obstante, a Reforma conduzida pelo professor Trindade, trouxe em seu bojo novas concepções filosóficas e pedagógicas, e que de certa forma provocaram alterações no contexto escolar. Entretanto, algumas interrogações podem ser feitas quanto ao impacto desta reforma, principalmente no campo reservado às bibliotecas escolares, e que fundamentalmente motivaram a realização do estudo do autor deste artigo. As novas concepções introduzidas pela Reforma de 1935 sinalizavam a instalação e o desenvolvimento de bibliotecas nos estabelecimentos de ensino? Quis as estratégias utilizadas para a dinamização deste espaço junto à comunidade escolar? Que representações passam a ter os livros e a leitura no âmbito da reforma?

Diante das interrogações postas, o presente trabalho tem como foco principal investigar a implantação das bibliotecas escolares à luz do Decreto nº 713 de 05 de janeiro 1935 e, particularmente, o teor das Instruções aprovadas pela Portaria $n^{\circ} 4$ de janeiro de 1937, cujas recomendações estabeleciam a organização das bibliotecas escolares na rede oficial de ensino. Para a consecução da investigação, analisou-se ainda, parte da produção documental oficial impressa e manuscrita, encontrada em atas, periódicos oficiais, circulares, relatórios, portarias e decretos, pertencentes ao acervo da Biblioteca Pública do Estado, Biblioteca da Assembleia Legislativa e Arquivo do Conselho Estadual de Educação

\section{A REFORMA TRINDADE: DELIMITANDO A BIBLIOTECA ESCOLAR}

A Constituição Brasileira de 1934 instituiu medidas na área educacional, atribuindo à União a responsabilidade de estabelecer as diretrizes básicas, reservando aos Estados a incumbência de organizar e manter os seus sistemas educacionais em consonância com as diretrizes elaboradas pelo Governo Federal. Em conformidade com os dados do Instituto Brasileiro de Geografia e Estatística (IBGE), o estado catarinense registrava em 1932 um total de 1501 unidades escolares, sendo que 760 delas estavam sob controle administrativo do Governo do Estado, 293 escolas vinculadas aos municípios e 448 unidades 


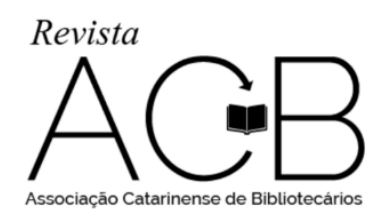

Revista ACB: Biblioteconomia em Santa Catarina, Florianópolis, v. 22, n. 3, p. 450-466, ago./nov., 2017.

de responsabilidade particular, perfazendo um total de 77.242 matrículas (BRASIL, 1942, p. 43). Ressalta-se que a reforma educacional promovida no Governo de Vidal Ramos a partir de 1910, conduzida pelo educador paulista Orestes Guimarães, manteve praticamente a mesma estrutura educacional até o ano de 1935, quando uma nova reforma do ensino catarinense volta a ser postulada.

Esta nova reformulação vai estar muito próxima das diretrizes alinhavadas no IV Congresso de Educação realizado na cidade de Fortaleza, mas, sobretudo, das reformulações produzidas no sistema de ensino do Distrito Federal, idealizado pelo educador escola novista Fernando de Azevedo (FIORI, 1975, p. 145). O texto introdutório do documento base da Reforma - o Decreto $\mathrm{n}^{\mathrm{o}} 713$ de 05 de janeiro de 1935, justificava entre outros aspectos, a “[...] necessidade de adoção de normas para regerem os Institutos destinados à formação do professorado, para aplicação de novos métodos de ensino [...]" (SANTA CATARINA, 1935, p. 1). A condução dos rumos da Reforma, ficou sob incumbência do professor Luiz Sanches Bezerra Trindade, com anuência do Governador Aristiliano Ramos.

Dentre as alterações inclusas no Decreto, destaca-se no artigo $3^{\circ}$, a criação do Departamento de Educação em substituição à Diretoria de Instrução Pública. O Departamento passou a ser constituído por Institutos e seis Sub-Diretorias, obedecendo a seguinte hierarquização: Instituto de Educação - voltado à formação do magistério e funcionalismo técnico; Sub-Diretoria Administrativa - encarregada pelo expediente, contabilidade, pessoal e arquivo; Sub-Diretoria Técnica - responsável pelos estudos e execução de planos, programas, métodos e processos de ensino, inspeção escolar e publicações; SubDiretoria de Saúde e Higiene Escolar - encarregada do serviço médico escolar e assistência dentária; SubDiretoria de Educação Física, Recreação e Jogos; Sub-Diretoria de Bibliotecas, Museus e Radiodifusão.

De acordo com essa nova estruturação, as Escolas Normais passam a ser denominados Institutos de Educação, abrangendo os Jardins de Infância, Grupos Escolares, Escolas Isoladas (rural) e as Escolas Normal Primária, Secundária e Superior Vocacional. Algumas alterações no currículo incluíram disciplinas como a pedagogia, psicologia e agricultura, além de prever a introdução de métodos objetivando facilitar a transmissão de conhecimentos pelos alunos mediante a observação direta, como por exemplo, as excursões escolares. Métodos estes, integrantes das concepções idealizadas pelos educadores vinculados à proposta da Escola Nova.

O Decreto balizador da reforma estabelecia, no Artigo 35, uma nova composição do corpo técnico funcional, instituindo nos Institutos de Educação os cargos de Secretário escolar, professores auxiliares para a Escola Normal Primária, Secundária e Superior, além de um professor bibliotecário para as Escolas Normais e um professor encarregado pelas bibliotecas escolares. A criação dos cargos reservados para as funções bibliotecárias demonstra uma preocupação de dispor nos Institutos e nos Grupos Escolares a 


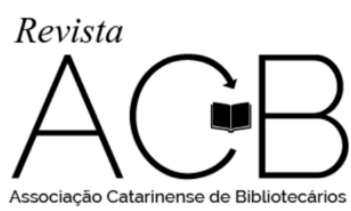

Revista ACB: Biblioteconomia em Santa Catarina, Florianópolis, v. 22, n. 3, p. 450-466, ago./nov., 2017.

instalação de bibliotecas voltadas aos professores e alunos, justificadas no Artigo 49, pela necessidade de despertar o interesse dos alunos pela "[...] boa leitura e servir de complemento às atividades escolares [...]" (SANTA CATARINA, 1935, p. 1).

\section{A CRIAÇÃO DOS CARGOS DE PROFESSORA BIBLIOTECÁRIA NA ESCOLA NORMAL}

Com a criação do Departamento de Educação, instituiu-se a Sub-Diretoria de Bibliotecas, Museus e Radiodifusão, órgão responsável pela implementação de ações voltadas para a instalação de uma rede de bibliotecas escolares na rede oficial de ensino. Um dos primeiros passos para a consecução do objetivo consistiu na obrigatoriedade dos Institutos de Educação e nos Grupos Escolares Modelo Dias Velho e Vidal Ramos, sediados respectivamente na Capital e em Lages, instituírem as suas bibliotecas. Dando sequência à execução das ações, foram criados nos respectivos estabelecimentos, os cargos de Professora Bibliotecária e Professora Encarregada de Bibliotecas Escolares e o de Professora bibliotecária na Escola Normal Superior e Superior Vocacional em Florianópolis, com salários iniciais de $290 \$ 00$ (DIÁRIO OFICIAL, 1938, p. 6) e a previsão de dotações orçamentárias com rubricas especificas voltadas para a compra dos acervos e encadernação dos volumes, estipulados em 1:200\$000 anuais para cada estabelecimento (DIÁRIO OFICIAL,1940, p. 11). Ademais, ao estabelecer estas ações, havia uma preocupação por parte do idealizador da reforma - Professor Trindade, em modificar a realidade em que estavam envoltas as bibliotecas no cenário escolar, não as deixando nos baixos índices de organização, quando respondia pela Diretoria de Instrução, conforme correspondência dirigida aos diretores dos estabelecimentos escolares:

Senhor Diretor: Foi com surpresa que verifiquei na organização dos mapas da estatística educacional de 1932, que, na maioria dos Grupos Escolares do Estado, pouco se tem feito para a organização das bibliotecas e manutenção das caixas escolares, instituições de grande utilidade para os quais recomendo mais uma vez toda atenção. Saúde e Fraternidade. Luiz Sanches Bezerra Trindade (SANTA CATARINA, 1941, p. 10).

E reafirmando a mesma preocupação, como pode se observar nas Atas das reuniões realizadas com os Inspetores Escolares, cujo assunto estava entre os pontos pautados:

b) Organização de Bibliotecas, Jornais, etc. Atendendo às inspirações da renovação educacional que se vai processando em nosso Estado, graças a concepção e aplicação da moderna ciência da educação, tem-se como inseparáveis dos aparelhos educativos os órgãos já consagrados como integrantes da eficiência escolar, e referentes as bibliotecas, caixas escolares, jornais, clubes agrícolas, etc. (SANTA CATARINA, 1948, p. 6).

Promover a inserção das bibliotecas escolares no cotidiano escolar mediante expedição de circulares e pautá-las nas reuniões oficiais, foram estratégias promovidas pelos responsáveis a fim de universalizá- 


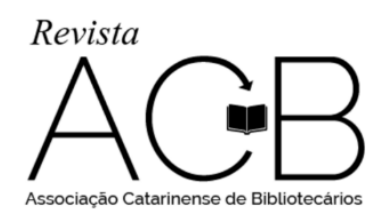

Revista ACB: Biblioteconomia em Santa Catarina, Florianópolis, v. 22, n. 3, p. 450-466, ago./nov., 2017.

las. Outra forma de promovê-las consistiu na utilização de veículos de informação, entre eles, a Revista de Educação - órgão do professorado catarinense. Na edição que circulou nos meses de janeiro e fevereiro de 1937, publicou-se um artigo enaltecendo o papel e a importância das bibliotecas como “[...] instrumento socializador na integração do movimento renovador educacional e complemento de máxima vitalidade dentro da Escola Ativa", enquanto que na "Seção Noticiário", informava a criação de bibliotecas móveis intituladas José Boiteux e Luiz Delfino (REVISTA DE EDUCAÇÃO, 1937, p. 4).

O acervo das bibliotecas móveis era composto por obras didáticas, literatura infantil e pedagógica, voltados para a divulgação e disseminação da leitura, tornando o livro objeto da cultura escolar, além de aproximá-lo junto às escolas onde não havia condições físicas para a constituição de bibliotecas nos moldes prescritos, principalmente nas áreas rurais, onde estes espaços inexistiam ou eram precários:

[...] Pelo menos, 90\% de nossas escolas, acham-se instaladas em casas inadequadas, sem que satisfaçam quase que nenhum requisito exigido para tal mister. São salas com dimensões que mal comportam 20 alunos, e, no entanto, vamos encontrar 50 e até mais, ou então faltam claros, caixilhos, pinturas, paredes esburacadas com frestas e buracos enormes. [...] Temos encontrado escolas instaladas em até cozinhas, servindo-se do fogão com carteira [...]. (REVISTA DE EDUCAÇÃO, 1936, p. 22-23).

Diante deste cenário, era compreensível que o desenvolvimento de bibliotecas escolares estivesse situado num patamar bem abaixo das pretensões almejadas pelos dirigentes do Departamento de Educação. De acordo com os dados contidos no Relatório de Governo, o número de estabelecimentos existentes em 1937 totalizavam 2.447, assim distribuídos: 971 escolas isoladas/reunidas vinculadas à Rede de Ensino Estadual; 706 escolas sob responsabilidade Municipal e 661 pertencentes à Rede Particular. Neste universo, as bibliotecas escolares estavam constituídas em apenas 135 escolas, das quais, 75 pertencentes à estrutura Estadual, 42 nas escolas Particulares e 18 subordinadas às escolas Municipais (SANTA CATARINA, 1938a, p. 45).

Nota-se que a organização das bibliotecas era bastante retraída, não atingindo a totalidade dos Grupos Escolares, estabelecimentos que sempre estiveram na vanguarda educacional. Contudo, nos Grupos Escolares localizados nas cidades de Florianópolis, Joinville, Blumenau, Laguna, Itajaí, Biguaçu e São Francisco do Sul, elas estavam constituídas (REVISTA DE EDUCAÇÃO, 1936, p. 55). No intuito de ampliar a instalação das bibliotecas nos demais estabelecimentos escolares, o Diretor da pasta do Interior e Justiça, órgão no qual o Departamento de Educação estava subordinado, expede a Portaria $\mathrm{n}^{\circ} 4$, contendo as Instruções, documento que regulamentava o Capítulo II do Decreto $\mathrm{n}^{\mathrm{o}} 713$ de 05 de janeiro de 1935, objetivando a instalação e organização de bibliotecas escolares no âmbito estadual. 


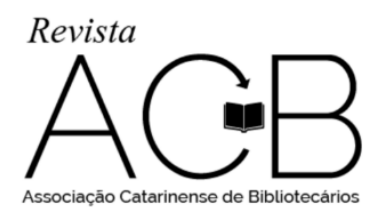

Revista ACB: Biblioteconomia em Santa Catarina, Florianópolis, v. 22, n. 3, p. 450-466, ago./nov., 2017.

Figura 1 - Instruções

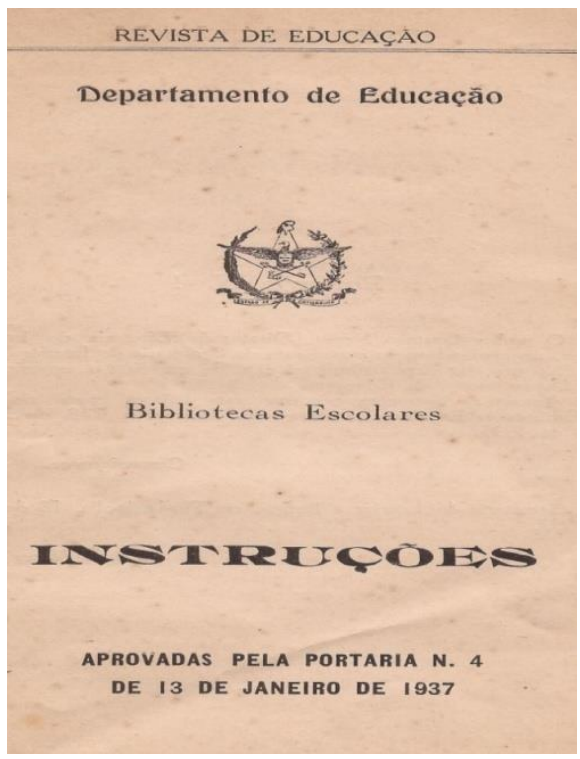

Fonte: Revista de Educação,1937.

\section{INSTRUÇÕES: UMA ANÁLISE DAS PRESCRIÇÕES ESTABELECIDAS}

A aplicação das Instruções, corpus documental constituído por 17 artigos e 5 anexos, pode ser entendido como uma ação pioneira, considerando que, pela primeira vez na legislação do ensino catarinense, as bibliotecas escolares foram agraciadas com um documento balizador, definindo atribuições no tocante à sua administração, organização e utilização pelo corpo discente e docente. Prevista para ser instituída em todos os níveis de instrução, o que incluía até os estabelecimentos isolados, a sua organização recaía ao corpo discente, categorizados como sócios, podendo também, ser instituída uma modalidade especial de sócios protetores - composta por pais e amigos da instrução, conforme os Artigos $1^{\circ}$ e $3^{\circ}$.

Apesar da não obrigatoriedade, no Parágrafo Único e no Artigo $4^{\circ}$, estava previsto o pagamento de uma contribuição mínima no valor de cem réis por sócio, não explicitando se o recolhimento deveria ser efetuado mensalmente ou anualmente. Além da contribuição financeira voluntária, poderiam ser organizadas atividades de cunho cultural e artístico em parceria com a comunidade escolar, no intuito de angariar recursos financeiros destinados para a manutenção das bibliotecas. E quanto à constituição dos seus acervos, quais os tipos de materiais autorizados prescritos nas Instruções? Além das obras que o Departamento de Educação recomendava para serem adotados nas escolas, livros classificados por gêneros e assuntos, periódicos e produção textual dos alunos poderiam ser incorporados aos acervos, com 


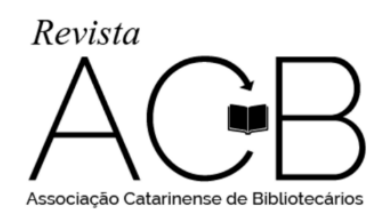

Revista ACB: Biblioteconomia em Santa Catarina, Florianópolis, v. 22, n. 3, p. 450-466, ago./nov., 2017.

o propósito de valorizar a atividade educativa e reforçar a aprendizagem, conforme as determinações contidas no Artigo 6 ${ }^{\circ}$ :

\begin{abstract}
As bibliotecas constarão de livros sôbre viagens, ciências naturais (tanto quanto possível sob forma atrativa), biografias, romances, memórias, trabalhos a respeito do Brasil, do Estado, poesias, dicionários, revistas e jornais ilustrados e outros de interesse educativo. E deverão ser enriquecidas com coletâneas feitas pelos próprios alunos com recortes de jornais, reunidos pelos assuntos: poesias fáceis, poesias para classes adiantadas, artigos sobre economia política, contos, contos infantis, charadas, notícias históricas e outros. Trará essa iniciativa ainda a vantagem de interessar as crianças pela leitura dos jornais, habituando-as a selecionar a parte sadia das publicações (REVISTA DE EDUCAÇÃO, 1937, p. 23-24).
\end{abstract}

Entretanto, a leitura de determinados livros, principalmente, aqueles cujos conteúdos eram classificados como "impróprios" e que deveriam ser evitados, tais como, os que versavam sobre misticismo, "os quais afasta a criança das realidades da natureza, perturbando a concepção que possa formar do mundo e das coisas', conforme Parágrafo Único do Artigo $6^{\circ}$ (REVISTA DE EDUCAÇÃO, 1937, p. 24). Em relação à circulação dos materiais que compunham o acervo, além de um conjunto de obras que poderiam ser consultadas no ambiente da biblioteca, o Artigo $7^{\circ}$ das Instruções, autorizava o acesso a determinadas categorias de livros (exclusivamente as de gênero literário) que poderiam circular no espaço doméstico, extrapolando assim o universo escolar, mediante empréstimos com prazos estipulados:

Art. 7. - Os livros da biblioteca serão distribuídos em duas categorias:

a) livros de consultas na sala da biblioteca, considerando-se nesse número os livros didáticos, o Tesouro da Juventude e outros de difícil aquisição e grande procura;

b) romances, livros de viagens e de contos, em suma, de todos quanto provoquem o interesse por uma leitura continuada, podendo então ser levado para casa, pelo prazo de uma semana (REVISTA DE EDUCAÇÃ̃, 1937, p, 24).

A utilização do espaço reservado à biblioteca passa a ser objeto de novas significações. De um local determinado a ser meramente depositário de livros, as Instruções recomendavam em seu Artigo $8^{\circ}$, a realização de uma série de atividades educativas, culturais e artísticas, voltadas a dinamização do espaço, estabelecendo rupturas com a prática silenciosa. As atividades sugeridas envolviam apresentações musicais, recitais de poesias, narrações, contos, canto, leituras de biografias e autobiografias, anedotários, charadas, dramatizações, relatórios de estudos, entre outras, com o propósito de desenvolver junto às crianças a "expressão e de dar-lhes desembaraço para falar em público" (REVISTA DE EDUCAÇÃO, 1937, p. 24).

No sentido de despertar o espírito democrático no ambiente escolar, a escolha do nome da biblioteca e da diretoria era realizada mediante processo eleitoral com votação secreta, eleitos pelos sócios. Dentre os critérios estabelecidos, o Patrono deveria recair em nome de pessoa que tivesse prestado 


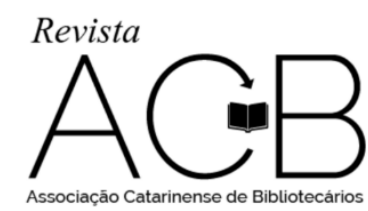

Revista ACB: Biblioteconomia em Santa Catarina, Florianópolis, v. 22, n. 3, p. 450-466, ago./nov., 2017.

relevantes serviços à Pátria, excluindo as pessoas vivas. Geralmente os escolhidos eram pessoas com atuação e destaque nas áreas políticas, militares, religiosas, bem como ex-diretores e professores. Parece que o critério de não homenagear pessoas vivas não foi seguido à risca, pois, encontramos em algumas bibliotecas, homenageados exercendo as funções de professores e inspetores. A condução da diretoria da biblioteca era exercida pelos cargos de presidente, vice-presidente, $1^{\circ}$ e $2^{\circ}$ secretários, $1^{\circ}$ e $2^{\circ}$ tesoureiros, $1^{\circ}$ e $2^{\text {a }}$ bibliotecário e auxiliar (Artigos $9^{\circ}$ e $10^{\circ}$ ). No documento encaminhado ao Departamento de Educação e veiculado no Diário Oficial do Estado, bem como o instante fotográfico representado na Figura 2, dão mostras da participação dos integrantes das escolas na organização das bibliotecas:

Na Escola Mista Estadual de São Martinho em Tubarão, foi criada a Biblioteca Escolar, tendo sido eleita e empossada a seguinte diretoria: Presidente: Waldemar Goulart; Vice: Adaulto dos Santos; $1^{\circ}$ Secretário Flavio Correa; $2^{\circ}$ Secretário: Elpidio da Silva; $1^{\circ}$ Tesoureiro: José A. dos Santos; $2^{\circ}$ Tesoureiro: Martinho M. Goulart; Auxiliares: Remi Boaventura, José V. Cascais e Nereu Rodrigues (DIÁRIO OFICIAL, 1944, p. 6).

A Figura 2 a seguir mostra a representação da eleição da diretoria da biblioteca escolar.

Figura 2 - Elegendo a diretoria da biblioteca escolar.

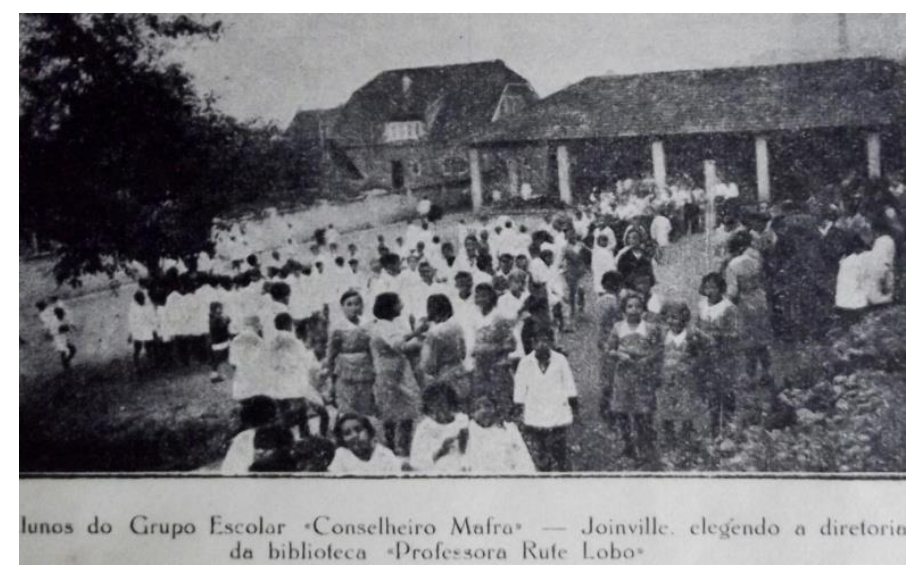

Fonte: Revista de Educação, 1936.

A distribuição de atribuições e responsabilidades aos alunos nas atividades da biblioteca, abriam possibilidades para um maior envolvimento e contato com os livros e a leitura, possibilitando ainda um melhor entendimento da organização do trabalho e da sociedade. Estas atribuições eram inerentes aos cargos ocupados, e envolviam funções de cunho administrativo (fiscalizar atos da diretoria, ordenamento de despesas, expedição de relatórios), financeiro (arrecadação de contribuições, pagamento de despesas) e de secretariado (material de expediente, atas), atribuições estas executadas sob responsabilidade da presidência, tesouraria e secretaria, respectivamente. Em relação aos demais membros que exerciam os cargos de bibliotecários e auxiliares, eram atribuídas uma série de responsabilidades, tais como a guarda, 


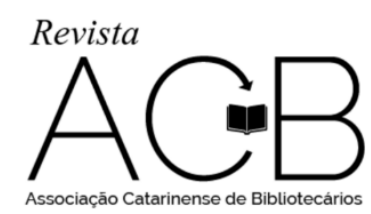

Revista ACB: Biblioteconomia em Santa Catarina, Florianópolis, v. 22, n. 3, p. 450-466, ago./nov., 2017.

organização dos fichários de assuntos, orientação, prevenção e cuidados com o acervo, controle de estatísticas (consultas, empréstimos, frequência à biblioteca), orientação de pesquisas e aplicação de sanções punitivas aos sócios que tivessem condutas inadequadas quanto ao zelo dos materiais escolares.

Segundo Nagle (1976), que efetuou estudos acerca do desenvolvimento da educação brasileira na Primeira República, as delegações de responsabilidades imprimiam uma marca dos princípios da Escola Nova, cujas atividades escolares não deveriam ser realizadas pelos alunos isoladamente, mas na medida do possível através de grupos, atribuindo a cada indivíduo responsabilidades na execução do trabalho. Para o autor, a organização da classe escolar equiparava-se a uma "pequena oficina de vida e trabalho em comum, onde cada aluno levasse a tarefa coletiva a sua contribuição pessoal, trabalhando todos não para o mestre, mas antes para a pequena sociedade de que fazem parte" (NAGLE, 1976, p. 256). Apesar de elevar o exercício democrático e participativo contidos nas Instruções, o Capítulo reservado às disposições gerais - Artigos 13 e 15, apresenta resquícios de uma forte centralização e controle exercidos pela direção do estabelecimento escolar, representada por encontros quinzenais com a diretoria da biblioteca. Auxiliada pelos professores, cabia à direção escolar inferir na organização e aquisição dos livros, revistas jornais e demais materiais do acervo, remetendo semestralmente ao Departamento de Educação as informações exigidas no Anexo $\mathrm{n}^{\circ} 5$.

Figura 3 - Ficha Relatório Anexo 5

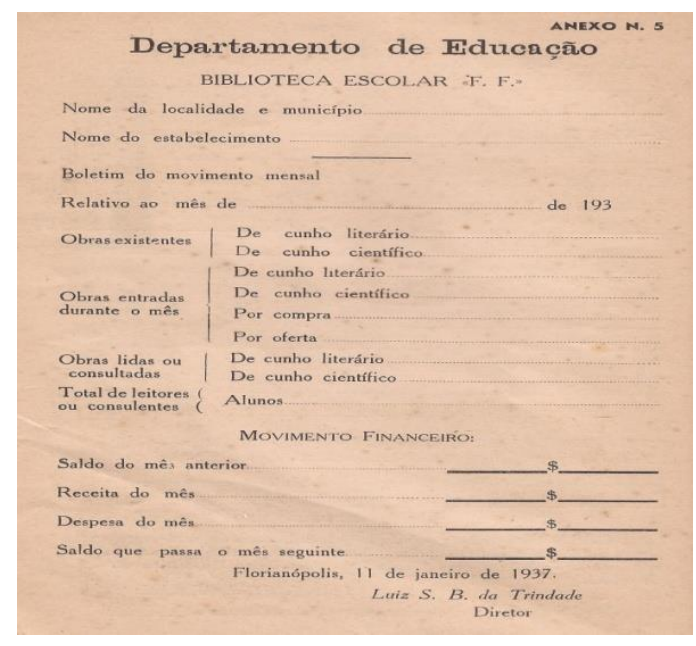

Fonte: Revista de Educação, 1937.

A centralização e formalização das atividades executadas na área educacional, e que não diferenciava da situação nacional vivenciada no decorrer do Estado Novo, foi considerada por Anísio Teixeira (apud Fiori, 1975 p. 157) como um “[...] excesso de centralização e de multiplicação de 


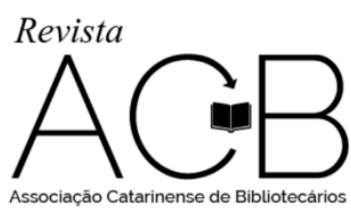

Revista ACB: Biblioteconomia em Santa Catarina, Florianópolis, v. 22, n. 3, p. 450-466, ago./nov., 2017.

dispositivos legais, minuciosos, com o objetivo de acentuar a unidade nacional, transformando em uma atividade estritamente controlada por Leis e Regulamentos [...]”, reservando ao Ministério da Educação e as Secretarias de Educação estaduais o papel de fiscalização, registro e controle dos dispositivos legais previstos. Nesse sentido, as bibliotecas também estavam enquadradas no "controle formal", e todas as ações seriam fiscalizadas e orientadas por diretores e professores, que prestavam contas ao Departamento de Educação através dos relatórios, preenchendo as informações do Anexo n5.

O empenho dos administradores escolares visando revalorizar o papel das bibliotecas extrapolavam o ambiente escolar, e buscavam o apoio da comunidade, conforme percebemos na carta encaminhada pela empresa M. Ziplerer \& Cia da cidade de Rio Negrinho ao Superintendente Geral do Ensino:

\footnotetext{
Se hoje lhe passamos estas linhas fazemos isto especialmente com o intuito de elogiar sobre modo a obra que vossa senhoria dentro de pouco tempo que está trabalhando como Diretor do Grupo Professora Maria Tavares. Com o máximo interesse, acompanhamos também o desenvolvimento da biblioteca, porém reparamos que, para guardar bem as diversas obras, em parte de certo valor, falta um arquivo próprio para tal fim. Assim, resolvemos mandar um armário e uma mesa para a sala da biblioteca e pedimos V. S. a fineza de aceitar estes móveis com sinal de alta consideração. Rio Negrinho, 05 de setembro de 1939 (DIÁRIO OFICIAL, 1939, p. 2).
}

No telegrama encaminhado pelos responsáveis do Grupo Escolar Conselheiro Mafra de Joinville, observa-se a utilização do rádio como importante veículo de divulgação e de aproximação entre biblioteca-comunidade:

[...] Professor Manoel Coelho cooperação de diretores de escolas locais organizam Biblioteca Escolar. Instituição encontrou apoio no meio social. Estação de rádio vem fazendo propaganda diariamente. Diretoria eleita já angariou um conto e quinhentos mil réis para livros didáticos. Biblioteca será instalada vossa presença, bem como órgão do G. E. Conselheiro Mafra, podendo solenidade realizarem-se entre os dias vinte e seis e trinta do corrente. Convém presença aqui Professor Areão. Saudações (DIÁRIO OFICIAL, 1939, p. 3).

A interação com a comunidade contava ainda com o apoio de algumas entidades, entre as quais, a Bandeira Paulista de Alfabetização e a American Library Association - ALA, instituição norte-americana que atuava internacionalmente através do projeto "Livros para a América Latina", objetivando estimular o desenvolvimento da leitura e de bibliotecas, além de contemplar com recursos financeiros as seguintes bibliotecas: Biblioteca Pública de Blumenau, Biblioteca Pública do Estado e as Bibliotecas escolares vinculadas ao Colégio Catarinense e Instituto Estadual de Educação (DIÁRIO OFICIAL, 1944, p. 2).

A Circular emitida pelo então Superintendente Interino de Ensino- Professor Elpídio Barbosa e dirigida aos Inspetores, Diretores de Grupos Escolares e Professores de Escolas Isoladas, recomendava uma série de atividades que deveriam reverter financeiramente em prol do desenvolvimento das bibliotecas, principalmente na composição de obras para o acervo, tais como a realização de sessões de 


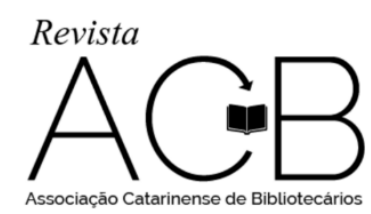

Revista ACB: Biblioteconomia em Santa Catarina, Florianópolis, v. 22, n. 3, p. 450-466, ago./nov., 2017.

cinema com cobrança de ingressos, venda de jornais velhos e garrafas e pedidos de doação de livros junto a autores, livrarias (SANTA CATARINA, 1943a).

Diante da recomendação, diversas escolas passam a promover e organizar atividades voltadas para a obtenção de fundos financeiros, revertendo na aquisição de livros para compor o acervo. As atividades aconteciam nas suas mais variadas formas, indo desde a venda de refrescos e ingressos para assistir sessões teatrais, conforme atestam algumas correspondências encaminhadas ao Departamento de Educação:

Grupo Escolar Rui Barbosa de Joinville: com o máximo prazer científico comunico voz que no dia 21 do mês corrente, realizou-se um festival em benefício da Biblioteca, constante de sorteios de prendas e venda de refresco e sanduíche. A renda líquida foi de CR \$ 820,70, importância que será empregada na compra da Coleção tesouro da Juventude. Filomeno Cardoso, Diretor (DIÁRIO OFICIAL, 1943a, p. 7)

Grupo Escolar Santo Antônio de Ituporanga: Tenho o prazer de levar ao vosso conhecimento que durante a "Semana de Caxias", levada a feito por este Educandário, foi realizada também a "Semana da Garrafa", cuja rende atingiu a importância de CR\$ 144,50. Desta importância reverterá em benefício da Biblioteca Escolar deste estabelecimento, e será empregada na compra de novos livros para professores e alunos; Guido Costa, Diretor (DIÁRIO OFICIAL, 1943a, p. 2).

Todas estas campanhas caminhavam concomitantemente com as novas práticas escolares introduzidas no cotidiano escolar. Era papel específico da escola ofertar condições ou os meios suficientemente amplos para a universalização da leitura discente. Para Vidal (2000, p. 506), a escola deveria "enfatizar o recurso à leitura em silêncio, ao mesmo tempo em que teria de disponibilizar maior quantidade de livros ao público escolar, garantir a sua qualidade e abolir a orientação do livro único"

\section{OS CLUBES E AS NOVAS MODALIDADES DE LEITURA: ALIADOS NA CONSTRUÇÃO DA BIBLIOTECA ESCOLAR}

No intuito de estimular a presença dos alunos a frequentar o espaço biblioteca, era sugerido ao corpo de professores algumas estratégias, tais como:

\footnotetext{
1) a leitura de histórias interessantes e dizendo: Histórias como estas são encontradas no livro "tal" da biblioteca escolar; 2) Iniciando, sem terminar, o conto de uma história, e indicando a página do livro que a contém e que pode ser procurado na biblioteca escolar; 3) Fazendo uma pergunta e pedindo aos alunos que vão procurar a resposta em uma página de determinado livro da biblioteca escolar (DIÁRIO OFICIAL, 1943a, p.78-79).
}

Contudo, serão as recomendações presentes no Programa de Leitura do Terceiro e Quarto Ano do Curso Primário (SANTA CATARINA, 1943b, p. 135-136), que nortearão as ações dos professores no tocante ao desenvolvimento da leitura. No corpo deste documento, estavam contidos diversos procedimentos em que os professores deveriam utilizar para alcançar os objetivos para uma boa leitura: 


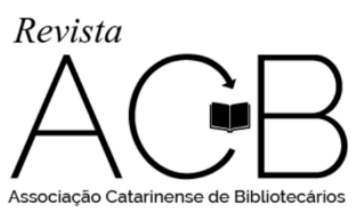

Revista ACB: Biblioteconomia em Santa Catarina, Florianópolis, v. 22, n. 3, p. 450-466, ago./nov., 2017.

[...] mas a boa leitura só se aprende pela imitação, e o melhor modelo é a leitura do mestre, que precisa tornar-se um bom leitor. É conveniente que a leitura em voz alta seja precedida sempre da leitura mental de toda a lição, destinando-se diariamente alguns minutos para esse exercício a que se deve cedo habituar a criança, pois essa maneira de ler para si, em silêncio é a mais utilizada na vida. [...] Deve-se constar do Programa desta classe a leitura suplementar em livro à altura do adiantamento dos alunos e que trate de lições de cousas, de assuntos históricos geográficos, etc sendo o seu principal objetivo auxiliar a aquisição do conhecimento (SANTA CATARINA, 1943b, p. 127-128).

Para a conservação da leitura expressiva, eram fundamentais o tom de voz, a boa articulação das palavras, as pausas e ligações, a respiração conveniente, bem como as posturas corporais e a compreensão dos assuntos. Daí a necessidade do preparo da lição e da escolha do livro, cujos assuntos precisavam estar à altura do entendimento do aluno. A prática da leitura oralizada tinha então um controle ritualizado, tanto em nível de posturas, como de conteúdo.

Entretanto, novas práticas de leitura começam a ser introduzidas no ambiente escolar, principalmente em decorrência das exigências advindas de uma sociedade mais urbanizada, possibilitando o acesso à escolarização das camadas populares, e a circulação de um volume maior de informações que a sociedade moderna passa a imprimir, exigindo dessa forma, uma leitura individualizada e rápida: a leitura silenciosa. Na concepção do educador norte-americano Willian Gray, esta modalidade de leitura permitiria alargar as experiências do leitor, sendo um "meio de ampliar as experiências dos meninos e das meninas, de estimular os seus poderes mentais e de ajudá-los a viver uma vida plena e tão rica quanto possível” (GRAY, 1933, p. 42-61). Não obstante, a leitura silenciosa também era recomendada pelo discurso médico, mediante estudos laboratoriais efetuados pelo movimento ocular, o que influirá na aquisição do ritmo da leitura de cada criança (SILVEIRA, 1960, p. 16). Estes estudos indicavam que a leitura silenciosa em comparação à oralização, ofereceria ao aluno um acesso maior de informações, contribuindo para a ampliação e intensificação dos ritmos de leituras, habituando o leitor para uma melhor seleção e apropriação das informações recebidas, concorrendo assim na "potencialização e ampliação de sua experiência como indivíduo" (VIDAL, 2000, p. 506).

Além das bibliotecas escolares, outros espaços passam a ser utilizados e reservados para a promoção e disseminação de hábitos desta nova modalidade de leitura: os Clubes de Leitura. Estas agremiações, que juntamente com as bibliotecas, faziam parte das Associações Auxiliares da Escola ${ }^{2}$ e que contavam com a organização dos alunos auxiliados pelos professores. Dados publicados pelo Departamento de Estatística e Publicidade do Estado de Santa Catarina revelam a existência destes Clubes em dois estabelecimentos de ensino particular no ano de 1932, elevando para seis em 1935, sendo

2 As Associações Auxiliares da Escola surgidas a partir de década de 1930, eram agremiações peri-escolar constituída pela Caixa Escolar, Biblioteca, Liga Pró-Língua Nacional, Clube de Leitura, Jornal Escolar, Pelotão de Saúde, Liga da Bondade, Círculo de Pais e Mestres, Clube Agrícola, Orfeão, Museu e Sopa Escolar. 


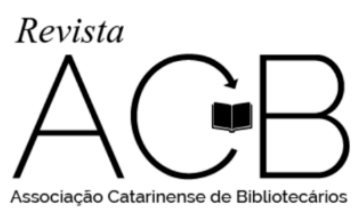

Revista ACB: Biblioteconomia em Santa Catarina, Florianópolis, v. 22, n. 3, p. 450-466, ago./nov., 2017.

que apenas dois em estabelecimentos municipais (SANTA CATARINA, 1938b, 117). A partir do início da Década de 1940, começam a ser instalados nas escolas estaduais, repercutindo num aumento bastante significativo, como podemos observar no Quadro abaixo:

\begin{tabular}{|l|c|c|c|l|||}
\hline \multicolumn{1}{|c|}{ QUADO } & $\mathbf{1 9 4 1}$ & $\mathbf{1 9 4 2}$ & $\mathbf{1 9 4 3}$ & $\mathbf{1 9 4 4}$ \\
\hline Número de Clubes & 152 & 180 & 202 & 222 \\
\hline
\end{tabular}

Fonte: Dados organizados pelo autor extraídas do Diário Oficial. 03 Jun.1949.

A leitura do Quadro exposto, permite supor que o crescimento dos Clubes de Leituras verificado a partir do início da Década de 1940, esteja vinculado a partir das recomendações efetuadas pelo Departamento de Educação e dirigidas às escolas estaduais, nas quais estabeleciam:

\begin{abstract}
Em estabelecimentos de ensino, serão organizados um ou mais Clubes de Leitura entre os alunos de classes mais adiantadas (em Grupo Escolar entre os alunos do Terceiro e Quarto ano). O Clube terá por fim: 1) estimular a leitura de bons livros e favorecer o desenvolvimento pelo gosto na escolha das obras; 2) Promover a leitura em voz alta e a audição inteligente por parte do auditório infantil que assistir a leitura; [...] 4) aumentar a biblioteca escolar pelo próprio esforço dos membros dos Clubes (SANTA CATARINA, 1943c, p. 76-77).
\end{abstract}

Além de intensificar o hábito da leitura, os alunos eram preparados para desenvolver o espírito associativo, literário e a integração entre as diversas classes, bem como estimular a frequência nas bibliotecas escolares, tornando-as assim, num espaço educativo e cultural, servindo também como "centros de interesses"3 de ensino e aprendizagem.

\title{
6 CONSIDERAÇÕES FINAIS
}

Ao criar a Sub-Diretoria de Bibliotecas, Museus e Radiodifusão subordinado ao Departamento de Educação, bem como os cargos de Professora Bibliotecária e Professora Encarregada das Bibliotecas Escolares, os dirigentes condutores dos rumos da educação catarinense dão início à pavimentação de uma política voltada para a constituição e organização de bibliotecas escolares na rede pública estadual. De forma inédita na legislação do ensino catarinense, a criação de uma nova categoria profissional junto aos Institutos de Educação nas cidades de Lages e Florianópolis e nos Grupos Modelos anexos, estabeleceu

\footnotetext{
${ }^{3}$ No Brasil, esta proposta foi introduzida a partir da Reforma elaborada por Fernando de Azevedo (1927-1930) na instrução pública do Rio de Janeiro, onde o ensino passa a estar pautado na integração das matérias e ser estimulado a partir de interesses. Neste sentido foram criados museus e laboratórios, que eram constituídos mediante obtenção de materiais recolhidos ou criados pelos alunos, servindo como reforço às atividades de ensinoaprendizagem.
} 


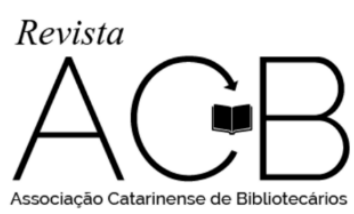

Revista ACB: Biblioteconomia em Santa Catarina, Florianópolis, v. 22, n. 3, p. 450-466, ago./nov., 2017.

dispositivos para a introdução de novas práticas, incorporando na formação dos "futuros professores" metodologias para uma melhor utilização dos livros, da leitura e o uso mais racional das bibliotecas.

A introdução destas novas práticas aproximou-se das concepções defendidas pelos adeptos do movimento Escola Nova, com destaque para as administrações de Fernando Azevedo (1927-1930) e Anisio Teixeira (1931-1935), que à frente da Instrução Pública do Distrito Federal, imprimiram substanciais alterações na organização das bibliotecas das Escolas Primárias, Complementares e Normal, e que resultaram na criação do cargo de bibliotecário para gerenciamento do acervo, escrituração em livro tombo, aquisições de materiais, estatísticas, horários destinados para leitura, pesquisa bibliográfica, entre outras inovações.

A construção de todo um discurso pautado na renovação da escola brasileira proporcionou o surgimento de novos conceitos e que acabaram alterando todo um modelo escolar existente modificando a sua estrutura tradicional. A junção de novas práticas e saberes em oposição às formas tradicionais até então vigentes, acabaram suscitando e construindo novas representações e ressignificações na cultura escolar. A organização de bibliotecas nas escolas catarinenses até o advento da Reforma Trindade, contempla índices relativamente baixos, sobretudo, nas escolas sob dependência administrativa estatal, conforme observamos no Quadro abaixo:

\begin{tabular}{|c|c|c|c|c|}
\hline \multirow{2}{*}{$\begin{array}{c}\text { ANO } \\
1932 \\
\end{array}$} & \multicolumn{3}{|c|}{ Dependência Administrativa } & \multirow{2}{*}{$\begin{array}{c}\text { TOTAL } \\
100\end{array}$} \\
\hline & 36 & - & 64 & \\
\hline 1933 & 35 & 03 & 03 & 107 \\
\hline 1934 & 46 & 09 & 09 & 132 \\
\hline 1935 & 54 & 09 & 09 & 146 \\
\hline $1936 *$ & - & - & - & - \\
\hline 1937 & 75 & 18 & 18 & 135 \\
\hline 1938 & 124 & 51 & 51 & 213 \\
\hline 1939 & 132 & 78 & 78 & 242 \\
\hline 1940 & 186 & 70 & 70 & 299 \\
\hline 1941 & 326 & 171 & 171 & 540 \\
\hline 1942 & 345 & 174 & 174 & 560 \\
\hline 1943 & 384 & 205 & 205 & 636 \\
\hline
\end{tabular}

Fonte: Sinopse Estatística do Estado, 1938; O Ensino no Brasil. 1937 a 1943. * Dados não encontrados.

Ao cruzarmos os dados, percebemos que as escolares particulares até a metade da década de 1930 detinham em comparação com a rede pública, um número bastante superior de bibliotecas. Entretanto, este cenário foi revertido a partir do ano em que são publicadas as Instruções, continuando em ascendência nos anos posteriores. O total de 636 bibliotecas existentes no ano de 1943, corresponde em 


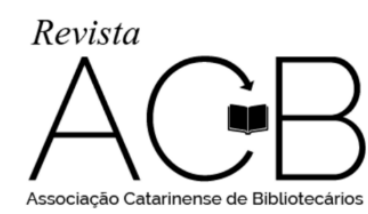

Revista ACB: Biblioteconomia em Santa Catarina, Florianópolis, v. 22, n. 3, p. 450-466, ago./nov., 2017.

índices percentuais a 26,5\%, sob um universo que totalizavam 2.598 escolas. É a partir deste período que a instalação das bibliotecas começa a atingir níveis de organização, mantendo uma posição de destaque no cenário educacional brasileiro, despontando como o quinto maior polo de concentração, ficando atrás dos estados de São Paulo, Minas Gerais, Rio Grande do Sul e Distrito Federal (MACHADO, 2002, p. 107).

Apesar dos esforços efetuados pelos integrantes do Departamento de Educação, no sentido de inserir as bibliotecas no universo escolar, o conjunto de ações acabaram não sendo implementadas de forma horizontalizada, ou seja, alguns segmentos foram abrangidos na sua totalidade, entre os quais os Grupos Escolares, Escolas Normais e Institutos de Educação, enquanto que na grande parte das Escolas Isoladas e Reunidas foram alijadas do processo de instalação destas bibliotecas.

Eventos culturais e artísticos, articulações comunitárias e escolares, criação de clubes e programas de leitura, atribuições e responsabilidades ao corpo discente, Bibliotecas Circulantes, bem como a exaustiva cobrança dos inspetores escolares e diretores nas reuniões pedagógicas, manifestadas nas recomendações prescritas nas Circulares emitidas pelo Departamento de Educação, podem ter sido algumas das estratégias formuladas no sentido de fortalecer a biblioteca como espaço socializador, gerador de informações e conhecimentos, e que possibilitou aos atores sociais envolvidos, a elaboração de novos significados para que os livros e as bibliotecas assumissem um papel relevante nas relações pedagógicas da escola.

\section{REFERÊNCIAS}

BRASIL. IBGE. Atlas do ensino no Brasil: breviário numérico e cartográfico ao $8^{\circ}$ Congresso Brasileiro de Educação. Rio de Janeiro: IBGE, 1942. 71p.

Ministério da Educação e Saúde. Serviço de Estatística. O Ensino no Brasil. Anos 1937 a 1943. Rio de Janeiro: Serviço Gráfico do IBGE.

DIÁRIO DA ASSEMBLEIA LEGISLATIVA DO ESTADO DE SANTA CATARINA. Florianópolis, v. 5, n.12, p. 129-132, 11 jul.1951.

DIÁRIO OFICIAL DO ESTADO DE SANTA CATARINA. Florianopolis, v.6, n.1592, 19 set. 1939. 8p

.Florianópolis, v.7, n.1899, 28 nov. 1940. 32p.

, Florianópolis, v. 9, n. 2230, 01 abr. 1942. 8p.

. Florianopolis, v.10, n.2584, 17 set. 1943. 8p.

. Florianópolis, v.11, n.2711, 02 abr. 1944. 8p. 


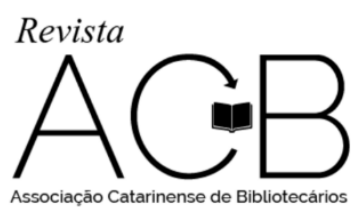

Revista ACB: Biblioteconomia em Santa Catarina, Florianópolis, v. 22, n. 3, p. 450-466, ago./nov., 2017.

Florianópolis, v. 16, n.3952, 03 jun.1949. 8p.

FIORI, Neide de Almeida. Aspectos da evolução do ensino público: ensino público e política de assimilação cultural no Estado de Santa Catarina nos períodos imperial e republicano. Florianópolis: EDEME, 1975. 218p.

GRAY, Willian. Principais reformas modernas do ensino da leitura. Educação, Rio de Janeiro, v.4, n 4. dez. 1933.

LOURENÇO FILHO, Manoel B. O Ensino e a biblioteca. Rio de Janeiro: Imprensa Nacional, 1944.

MACHADO, Alzemi. A Implantação de bibliotecas escolares na rede de ensino de Santa Catarina (décadas de 30 e 40. 123 f. 2002. Dissertação (Mestrado em Educação e Cultura) - Centro de Ciências da Educação, Universidade do Estado de Santa Catarina, Florianópolis. 2002.

NAGLE, Jorge. Educação e sociedade na primeira república. São Paulo: EPU; Rio de Janeiro: FENAME, 1974. 191p.

REVISTA DE EDUCAÇÃO: revista pedagógica. Florianópolis, n. 4-5, set/out., 1936. 56 p. Florianópolis, n. 6, nov/dez., 1936. 48 p. Florianopolis, n. 7, jan/fev., 1937. 52 p.

SANTA CATARINA. Governo do Estado. Decreto 713 de 05 de janeiro de 1935, aprova as reformulações na educação pública estadual. Diário Oficial do Estado de Santa Catarina. Florianópolis, v.1, n. 248, p.1, 10 jan. 1935. 8p.

Secretaria do Interior e Justiça. Departamento de Educação. Portaria n. 4 de 13 de janeiro de 1937, que aprova as Instruções para organização das bibliotecas escolares. Florianópolis. 1937.

Departamento de Educação. Livro de atas de reuniões de inspetores escolares - 1936 - 1948. Florianópolis: Conselho Estadual de Educação. Documentos avulsos Coleção Elpídio Barbosa.

Governo do Estado. Relatório do Interventor Federal de Santa Catarina Dr. Nereu Ramos ao Presidente da República. Florianópolis: IOESC, 1938a. 166p.

Departamento de Estatística e Publicidade. Sinopse Estatística do Estado n. 2. Florianópolis : IOESC, 1938b. 27p.

Secretaria do Interior e Justiça. Departamento de Educação. Circular no 13 de 08 de agosto de 1933. Circulares 1930-1941. Florianópolis: IOESC. 1943a.

Secretaria de Justiça, Educação e Saúde. Departamento de Educação. Circulares de 1942. Florianópolis : IOESC. 1943b.

Secretaria do Interior e Justiça. Departamento de Educação. Circular nº 09 de 28 de janeiro de 1941. Circulares 1930-1941. Florianópolis: IOESC. 1943c. 


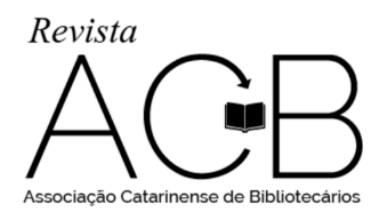

Revista ACB: Biblioteconomia em Santa Catarina, Florianópolis, v. 22, n. 3, p. 450-466, ago./nov., 2017.

SILVEIRA, Juracy. Leitura na escola primária. 2. ed. Rio de Janeiro : Conquista, 1960. 314p.

VIDAL, Diana Gonçalves. Escola nova e processo educativo. In: LOPES, liane Marta Teixeira; FARIA FILHO, Luciano Mendes de; VEIGA, Cynthia Greive (Orgs). 500 anos de educação no Brasil. 2 ed.

Belo Horizonte : Autêntica, 2000. 608 p.

\title{
THE 1935 REFORM: SIGNALIZING THE CONSTITUTION OF SCHOOLS LIBRARIES OF THE EDUCATIONAL SYSTEM FROM THE STATE OF SANTA CATARINA
}

\begin{abstract}
The present article investigates the reform of the education in Santa Catarina that occurred in 1935, since the approved Instructions by the Ordinance No. 04 on January 13th, 1937, a regulatory document which contains the recommendations for Schools Libraries of the Public Educational System of Santa Catarina. For the investigation attainment, was defined guiding principles with the objective of verifying which means and strategies were used by the political leaders from the Educational Department, as well as the representations that books and reading acquired during the reform, since the established prescriptions of the official documentation.
\end{abstract}

Key-words: Educational Reform. Educational Legislation. School Library.

\author{
ALZEMI MACHADO \\ Mestre em Educação e Cultura pela Universidade do Estado de Santa Catarina (UDESC). \\ Bacharel em Biblioteconomia pela Universidade do Estado de Santa Catarina (UDESC). \\ Bibliotecário da Biblioteca Pública do Estado de Santa Catarina. \\ E-mail: alzemi@fcc.sc.gov.br
}

RECEBIDO EM: 24-03-2017

ACEITO EM: 05-05-2017 